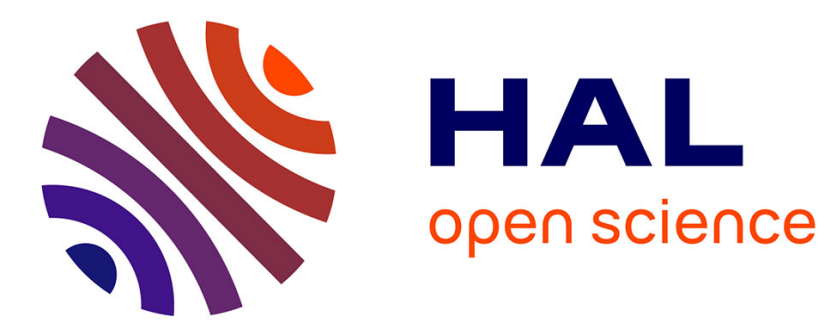

\title{
N-3 polyunsaturated fatty acids prevent the defect of insulin receptor signaling in muscle
}

Mohammed Taouis, Carine Dagou, Céline Ster, Georges Durand, Michèle Pinault, Jacques Delarue

\section{- To cite this version:}

Mohammed Taouis, Carine Dagou, Céline Ster, Georges Durand, Michèle Pinault, et al.. N-3 polyunsaturated fatty acids prevent the defect of insulin receptor signaling in muscle. AJP - Endocrinology and Metabolism, 2002, 282 (3), pp.E664-E671. hal-02674875

\section{HAL Id: hal-02674875 \\ https://hal.inrae.fr/hal-02674875}

Submitted on 31 May 2020

HAL is a multi-disciplinary open access archive for the deposit and dissemination of scientific research documents, whether they are published or not. The documents may come from teaching and research institutions in France or abroad, or from public or private research centers.
L'archive ouverte pluridisciplinaire HAL, est destinée au dépôt et à la diffusion de documents scientifiques de niveau recherche, publiés ou non, émanant des établissements d'enseignement et de recherche français ou étrangers, des laboratoires publics ou privés. 
Mohammed Taouis, Carine Dagou, Céline Ster, Georges Durand, Michèle Pinault and Jacques Delarue

Am J Physiol Endocrinol Metab 282:664-671, 2002. First published Oct 30, 2001;

doi:10.1152/ajpendo.00320.2001

You might find this additional information useful...

This article has been cited by 11 other HighWire hosted articles, the first 5 are:

The effect of dietary fat content on phospholipid fatty acid profile is muscle fiber type dependent

A. Janovska, G. Hatzinikolas, M. Mano and G. A. Wittert

Am J Physiol Endocrinol Metab, April 1, 2010; 298 (4): E779-E786.

[Abstract] [Full Text] [PDF]

Long-Chain (n-3) Polyunsaturated Fatty Acids Prevent Metabolic and Vascular Disorders in Fructose-Fed Rats

V. Robbez Masson, A. Lucas, A.-M. Gueugneau, J.-P. Macaire, J.-L. Paul, A. Grynberg and D.

Rousseau

J. Nutr., October 1, 2008; 138 (10): 1915-1922.

[Abstract] [Full Text] [PDF]

Long-chain $n-3$ fatty acids enhance neonatal insulin-regulated protein metabolism in piglets by differentially altering muscle lipid composition

K. Bergeron, P. Julien, T. A. Davis, A. Myre and M. C. Thivierge

J. Lipid Res., November 1, 2007; 48 (11): 2396-2410.

[Abstract] [Full Text] [PDF]

Antisense oligonucleotides against the lipid phosphatase SHIP2 improve muscle insulin sensitivity in a dietary rat model of the metabolic syndrome

R. Buettner, I. Ottinger, C. Gerhardt-Salbert, C. E. Wrede, J. Scholmerich and L. C. Bollheimer Am J Physiol Endocrinol Metab, June 1, 2007; 292 (6): E1871-E1878.

[Abstract] [Full Text] [PDF]

Long-chain n-3 polyunsaturated fatty acids dissociate phosphorylation of Akt from phosphatidylinositol 3'-kinase activity in rats

C. Le Foll, C. Corporeau, V. Le Guen, J.-P. Gouygou, J.-P. Berge and J. Delarue

Am J Physiol Endocrinol Metab, April 1, 2007; 292 (4): E1223-E1230.

[Abstract] [Full Text] [PDF]

Updated information and services including high-resolution figures, can be found at:

http://ajpendo.physiology.org/cgi/content/full/282/3/E664

Additional material and information about AJP - Endocrinology and Metabolism can be found at: http://www.the-aps.org/publications/ajpendo

This information is current as of September 3, 2010 .

AJP - Endocrinology and Metabolism publishes results of original studies about endocrine and metabolic systems on any level of organization. It is published 12 times a year (monthly) by the American Physiological Society, 9650 Rockville Pike, Bethesda MD 20814-3991. Copyright (C) 2002 by the American Physiological Society. ISSN: 0193-1849, ESSN: 1522-1555. Visit our website at http://www.the-aps.org/. 


\title{
N-3 Polyunsaturated fatty acids prevent the defect of insulin receptor signaling in muscle
}

\author{
MOHAMMED TAOUIS, ${ }^{1}$ CARINE DAGOU,${ }^{1}$ CÉLINE STER,${ }^{1}$ GEORGES DURAND, ${ }^{2}$ \\ MICHÈLE PINAULT, ${ }^{3}$ AND JACQUES DELARUE ${ }^{4}$ \\ ${ }^{1}$ Station de Recherches Avicoles, Institut National de la Recherche Agronomique Centre de Tours, \\ 37380 Nouzilly; ${ }^{2}$ Laboratoire de Nutrition et Sécurité Alimentaire, 78352 Jouy-en-Josas; ${ }^{3}$ Laboratoire \\ de Nutrition Centre Hospitalier Universitaire de Tours, 37044 Tours Cedex; and ${ }^{4}$ Medecine4-Nutrition \\ and Equipe Associée 948 Centre Hospitalier Universitaire, 29200 Brest, France
}

Received 17 July 2001; accepted in final form 2 November 2001

\begin{abstract}
Taouis, Mohammed, Carine Dagou, Céline Ster, Georges Durand, Michèle Pinault, and Jacques Delarue. N-3 Polyunsaturated fatty acids prevent the defect of insulin receptor signaling in muscle. Am $J$ Physiol Endocrinol Metab 282: E664-E671, 2002. First published October 30,$2001 ; 10.1152$ /ajpendo.00320.2001.-A high-fat diet containing polyunsaturated fatty acids (PUFA: n-3 or n-6) given for 4 wk to 5-wk-old male Wistar rats induced a clear hyperglycemia $(10.4 \pm 0.001 \mathrm{mmol} / \mathrm{l}$ for $\mathrm{n}-6 \mathrm{rats}$ and $10.1 \pm 0.001$ for $\mathrm{n}-3 \mathrm{rats})$ and hyperinsulinemia $(6.6 \pm 0.8 \mathrm{ng} / \mathrm{ml}$ for $\mathrm{n}-6$ rats and $6.4 \pm 1.3$ for $n-3$ rats), signs of insulin resistance. In liver, both diets (n-3 and n-6) significantly reduced insulin receptor (IR) number, IR and IR substrate (IRS)-1 tyrosine phosphorylation, and phosphatidylinositol (PI) 3'-kinase activity. In contrast, in leg muscle, IR density, as determined by Western blotting, was not affected, whereas IR and IRS-1 tyrosine phosphorylation in response to insulin treatment was restored in animals fed with n-3 PUFA to normal; in n-6 PUFA, the phosphorylation was depressed, as evidenced by Western blot analysis using specific antibodies. In addition, PI 3'-kinase activity and GLUT-4 content in muscle were maintained at normal levels in rats fed with n-3 PUFA compared with rats fed a normal diet. In rats fed with n-6 PUFA, both PI 3'-kinase activity and GLUT-4 content were reduced. Furthermore, in adipose tissue and using RT-PCR, we show that both n-3 and n-6 PUFA led to slight or strong reductions in p85 expression, respectively, whereas GLUT-4 and leptin expression was depressed in n- 6 rats. The expression was not affected in $\mathrm{n}-3$ rats compared with control rats. In conclusion, a high-fat diet enriched in n-3 fatty acids maintained IR, IRS-1 tyrosine phosphorylation, and PI 3'kinase activity and total GLUT-44 content in muscle but not in liver. A high-fat diet (n-3) partially altered the expression of p85 but not that of GLUT-4 and leptin mRNAs in adipose tissue.
\end{abstract}

fat diet; insulin resistance; muscle; liver

AMONG ENVIRONMENTAL factors, dietary fat plays an important role in the induction of insulin resistance (29). Experimental studies conducted in rats have demonstrated that both the amount and the type of fatty acids ingested alter insulin sensitivity in target tissues (i.e.,

Address for reprint requests and other correspondence: M. Taouis, INRA centre de Tours, Station de Recherches Avicoles, 37380 Nouzilly France (E-mail : taouis@tours.inra.fr). muscle, adipose tissue, and liver) associated with glucose intolerance and obesity $(26,27)$. Insulin resistance in liver results from an increased flux through glucose6-phosphatase (21), whereas insulin resistance in peripheral tissues results from a defect in glucose transport (16) and/or glucose phosphorylation followed by a reduction in both the rate of muscle glycogen synthesis and glucose oxidation (22). Because these physiological alterations mimic those reported in patients with type 2 diabetes $(3,4)$, it is of interest to try to better understand their molecular basis. Defects in insulin signaling in peripheral tissues have been reported during a high-fat diet, but the alterations reported are not uniform between muscle and adipose tissue (10). In muscle, the total amount of insulin receptor was reduced without modification of the receptor affinity (11); insulin receptor substrate (IRS)-1 and IRS-2 proteins were not affected, although their phosphorylation was reduced (1); and the activation of phosphatidylinositol (PI) 3'-kinase was reduced $(1,36)$. In addition, an alteration in intrinsic activity (23), translocation (36), or expression (14) of GLUT-4 has been observed. Taken together, these results suggest an impairment in the early steps of insulin signaling that could involve insulin receptor and IRS-1 tyrosine phosphorylation as well as PI 3 '-kinase activity. In adipose tissue, in contrast to muscle, a high-fat diet reduced the IRS-1 and IRS-2 proteins, whereas both the mRNA and the amount of GLUT-4 were reduced in muscle $(1,7,13$, 24). In liver, IRS-1 and IRS-2 proteins and their phosphorylation were not altered, and PI 3'-kinase activity associated with IRS-1 and IRS-2 was increased, suggesting that the alterations of insulin signaling responsible for the insulin resistance of liver differ from those implicated in the insulin resistance of peripheral tissues (1).

However, not all types of fatty acids induce an alteration of insulin action during a high-fat diet in rats (27). Indeed, the substitution of n-3 long-chain polyunsaturated fatty acid (PUFA) from fish oil for other

The costs of publication of this article were defrayed in part by the payment of page charges. The article must therefore be hereby marked "advertisement" in accordance with 18 U.S.C. Section 1734 solely to indicate this fact. 
types of lipids prevents insulin resistance $(12,17,28)$. The mechanisms sustaining such a protective effect of n-3 PUFA remain unclear. The effects of dietary n-3 PUFA could be related to the subsequent changes in fatty acid content in membrane phospholipids of insulin target tissues (14). In muscle, n-3 PUFA might improve insulin sensitivity through a relative increase in unsaturation of membrane phospholipids and/or a decrease in muscle content in triglycerides $(21,25,35)$. The alterations in membrane composition could affect insulin receptors (19) and/or IRS-1 and PI 3'-kinase expression and protein abundance (15). In adipose tissue, conversely to muscle, the defect in glucose transport induced by a high-fat diet is not affected by $n-3$ PUFA, which may result from reduced insulin receptor number and tyrosine kinase activity $(8,28)$. In liver, the impact of n-3 PUFA on insulin resistance is to date unclear. This effect of n-3 PUFA could be the result of a prevention of the increased glucose cycle activity, either associated or not with reduced hepatic fatty acid oxidation, which is known to promote gluconeogenesis $(12,17,21)$. Taken together, these studies suggest that n-3 PUFA may have a tissue-specific impact in restoring insulin sensitivity. However, the early steps of insulin signaling have not been studied in liver and have been studied only partially in peripheral tissues from animals fed a high-fat diet.

In the present study, we examined the effects of a high-fat diet containing n-6 PUFA or one containing $n-6$ and n-3 PUFA on insulin signaling in liver, muscle, and mRNA expression of some components of insulin signaling in addition to leptin in adipose tissue.

\section{MATERIALS AND METHODS}

Animal care and tissue preparation. All animal studies were conducted in accordance with the principles and procedures outlined in the Institut National de la Recherche Agronomique Guide for the Care and Use of Laboratory Animals. Thirty male Wistar rats aged 5 wk were housed in a temperature-, humidity-, and light-controlled room. Rats were placed on a laboratory chow diet $(60 \%$ carbohydrates$12 \%$ lipids-28\% protein) and water ad libitum for the first 5 wk. Next, they were divided into three groups ( $n=10$ /group). Rats received either laboratory chow (control rats), a high-fat diet rich in n-6 PUFA (n-6 rats), or a high-fat diet rich in n-3 PUFA (n-3 rats). The laboratory chow contained, as a percentage of calories, $22 \%$ casein, $6 \%$ peanut oil, $8 \%$ canola oil, $58 \%$ starch, and $6 \%$ sucrose. The high-fat diet rich in n-6 PUFA contained $58 \%$ fat from safflower oil, $16 \%$ casein, $21 \%$ starch, and 5\% sucrose. The high fat-diet rich in n-3 PUFA contained $39 \%$ fat from safflower oil, $19 \%$ fat from fish oil, $16 \%$ casein, $21 \%$ starch, and $5 \%$ sucrose. The content in fatty acids of each diet is reported in Table 1 . The three groups of rats received these diets for $4 \mathrm{wk}$. Rat body weights and food consumption were measured every week. At the end of the 4-wk period, animals in each of the three groups were subdivided into two groups of five rats. One group received an intraperitoneal injection of saline, and the other group received an intraperitoneal injection of insulin $(100 \mathrm{mU} / \mathrm{kg})$. The treatment was performed in the morning. Treated animals were returned to their cages and fed their respective feed. Seven minutes later, animals were killed. After neck dislocation, blood was collected, and plasma was prepared
Table 1. Fatty acid content of the 3 diets (percent of total fatty acids)

\begin{tabular}{|c|c|c|c|}
\hline \multicolumn{4}{|c|}{ Saturated } \\
\hline 14:0 & 0.2 & 0.1 & 2.1 \\
\hline $16: 0$ & 7.6 & 6.6 & 9.7 \\
\hline $18: 0$ & 2.8 & 4.8 & 4.8 \\
\hline $20: 0$ & 1 & 0.3 & 0.3 \\
\hline $22: 0$ & 1.5 & 0.7 & 0.6 \\
\hline $24: 0$ & 0.7 & & \\
\hline$\Sigma$ & 13.9 & 12.5 & 17.5 \\
\hline \multicolumn{4}{|c|}{ Monunsaturated } \\
\hline $16: 1 \mathrm{n}-9$ & 0.2 & 0.1 & 3.6 \\
\hline $18: 1$ n-9 & 58 & 19.5 & 18.3 \\
\hline $20: 1$ n-9 & 1.3 & 0.2 & 0.6 \\
\hline $22: 1 \mathrm{n}-9$ & 0.4 & & 0.2 \\
\hline $24: 1 \mathrm{n}-9$ & & & 0.1 \\
\hline$\Sigma$ & 59.9 & 19.8 & 22.8 \\
\hline \multicolumn{4}{|c|}{ n-6 Polyunsaturated } \\
\hline $18: 2 n-6$ & 22.4 & 67.4 & 49 \\
\hline $20: 2 n-6$ & & & \\
\hline $20: 3 n-6$ & & & \\
\hline $20: 4 n-6$ & & & 0.3 \\
\hline $22: 4$ n-6 & & & \\
\hline $22: 5$ n-6 & & & \\
\hline$\Sigma$ & 22.4 & 67.4 & 49.4 \\
\hline \multicolumn{4}{|c|}{ n-3 Polyunsaturated } \\
\hline $18: 3 \mathrm{n}-3$ & 3.8 & 0.1 & 0.8 \\
\hline $20: 5 n-3$ & & & 5.3 \\
\hline $22: 5 \mathrm{n}-3$ & & & 0.6 \\
\hline $22: 6 n-3$ & & & 3.6 \\
\hline$\Sigma$ & 3.8 & 0.1 & 10.3 \\
\hline
\end{tabular}

immediately and stored at $-20^{\circ} \mathrm{C}$ until subsequent analysis. Liver, leg muscles, and adipose tissue were collected, immediately frozen in liquid nitrogen, and stored at $-80^{\circ} \mathrm{C}$.

Determination of plasma glucose and insulin concentrations in fed rats. Plasma glucose concentrations were measured by the glucose oxidase method (Glucose Beckman Analyzer 2; Beckman, Palo Alto, CA). Plasma insulin concentrations were determined with an RIA kit (Linco Research, St. Louis, MO) using rat insulin standards.

Extraction and analysis of lipids. Total lipid extracts (from diets and rat tissues) were obtained by the method of Folch et al. (9). Triglycerides and phospholipids were separated and purified by using TLC on silica gel with hexane-diethyl etheracetic acid (70:30:1) as the developing solvent. Fatty acids were determined by direct methylation with boron trifluoride-methanol $\left(90 \mathrm{~min}\right.$ at $\left.100^{\circ} \mathrm{C}\right)$, and spots were scraped from TLC plates. Methyl esters of fatty acids obtained were diluted in hexane before separation by gas chromatography.

Determination of insulin receptor density in liver membranes. Liver membranes were prepared as previously described (30). Aliquots of $50-\mu \mathrm{l}$ crude membranes $(0.4 \mathrm{mg} / \mathrm{ml})$ were incubated for $16 \mathrm{~h}$ at $4^{\circ} \mathrm{C}$ with ${ }^{125} \mathrm{I}$-labeled insulin at 0.1 $\mathrm{ng} / \mathrm{ml}$ in the absence or presence of increasing concentrations of unlabeled monocomponent porcine insulin (4-40,000 ng/ $\mathrm{ml})$. The assay was terminated by centrifugation of the tubes at $12,000 \mathrm{~g}$ for $3 \mathrm{~min}$ at $4^{\circ} \mathrm{C}$. The pellets were washed with 0.2 $\mathrm{ml}$ chilled sucrose $(0.25 \mathrm{M})$, and radioactivity was counted. Nonspecific binding was determined in the presence of an excess of cold insulin. The competition curves were analyzed using Graph Pad software (version 2.00).

Immunoprecipitations and Western blotting procedures. Powdered tissues ( $1 \mathrm{~g}$ ) were homogenized, solubilized, and ultracentrifuged as previously described (6). The superna- 
tants were either directly submitted to Western blotting or to immunoprecipitation before Western blotting. For direct application, 10-20 $\mu \mathrm{g}$ of solubilized muscle proteins were submitted to SDS-PAGE and electrotransferred to nitrocellulose membranes. Next, membranes were incubated with different primary antibodies directed toward insulin receptor or GLUT-4. Blots were then revealed by enhanced chemiluminescence after incubation with horseradish peroxidase conjugated with specific secondary antiserum (Pierce). For the immunprecipitation procedure, $500 \mu \mathrm{g}$ of solubilized liver or muscle proteins were immunoprecipitated with an antiphosphotyrosine antibody $(\alpha-\mathrm{PY} 20 ; 1: 200)$ at $4^{\circ} \mathrm{C}$ over $16 \mathrm{~h}$. The immune complexes were precipitated with protein A-agarose for $1 \mathrm{~h}$ at $4^{\circ} \mathrm{C}$, as previously described (32). Immunoprecipitates were resolved by SDS-PAGE and transferred to nitrocellulose membranes, and Western blotting was performed as described above using $\alpha$-PY20 or $\alpha$-IRS- 1 (antibodies directed toward IRS-1).

PI 3'-kinase assay. PI 3'-kinase was determined as previously described $(18,31)$. Briefly, the liver and muscles were homogenized, solubilized, and ultracentrifuged. The supernatants were immunoprecipitated overnight at $4^{\circ} \mathrm{C}$ with $\alpha$-PY20 (1:200). PI 3'-kinase was measured in immunoprecipitates in the presence of phosphatidylinositol and labeled ATP. The radioactivity incorporated in phosphatidylinositol was quantified with a STORM apparatus (Molecular Dynamics).

Determinations of IR, IRS-1, p85, GLUT-4, and leptin expressions using RT-PCR in rat adipose tissue. Total RNAs from adipose tissue were extracted using an RNA Insta Pure kit according to the manufacturer's recommendations (Eurogentec). Total RNAs were submitted to RT-PCR as previously described (6). RT reactions were primed with random hexamer primers, and PCR was carried out in the presence of various pairs of primers. The PCR primers used were as follows: insulin receptor (IR), 5'-primer, 5'-TTTGGGATGGTTTATGAGGG-3', and $3^{\prime}$-primer, 5'-GCCAGGTCTCTGTGAACAAA-3'(flanking a region of $235 \mathrm{bp}$ ); IRS-1, 5'-primer, 5'-GCCCGGCCCACGAGGCTG-3', and 3'-primer, 5'-GCAATGCCTGTTGGCATG-3'(flanking a region of $490 \mathrm{bp}$ ); p85, 5' -primer, 5'-AACCTTCAACTCTGTGGTTG-3' , and 3'-primer, 5' -TGATTCTTTGCTGTACCGCT-3' (flanking a region of $336 \mathrm{bp}$ ); GLUT-4, 5' -primer, 5'-GAACATGGCGAACCCCCTAC-3', and 3'-primer, 5'-CTGCTGGCTCAGTGCAGCAC-3'(flanking a region of $800 \mathrm{bp}$ ); leptin, $5^{\prime}$-primer, 5'-ACACGTCGGTATCCGCCAAG-3', and 3'-primer, 5'-AGCAGATGGAGGAGGTCTCG-3' (flanking a region of $194 \mathrm{bp}$ ); 18S RNA, 5'-primer, 5'-CTGCCCTATCAACTTTCG-3', and 3'primer, 5'-GGCGTCGATCCTTATTAC-3' (flanking a region of $515 \mathrm{bp})$.

Statistics. Statistical analyses were performed using ANOVA to detect significant intergroup differences (ANOVA; STATVIEW software). Comparisons between two groups were performed by Student's unpaired $t$-test analysis. All results are expressed as means $\pm \mathrm{SE}$, and $P<0.05$ was considered statistically significant.

\section{RESULTS}

Basal parameters. Rats consuming a hyperlipidic diet (n-6 rats or n-3 rats) showed a significant $(P<$ 0.05 ) weight gain compared with rats receiving the control diet (control rats), as reported in Fig. $1 A$ and Table 2. The n-6 and n-3 rats consumed less feed after the second week of the diet (Fig. $1 B$ ), as indicated Table 2 and Fig. $1 B$ (expressed as g/day). The consumed energy calculated from these values shows that n-6 and
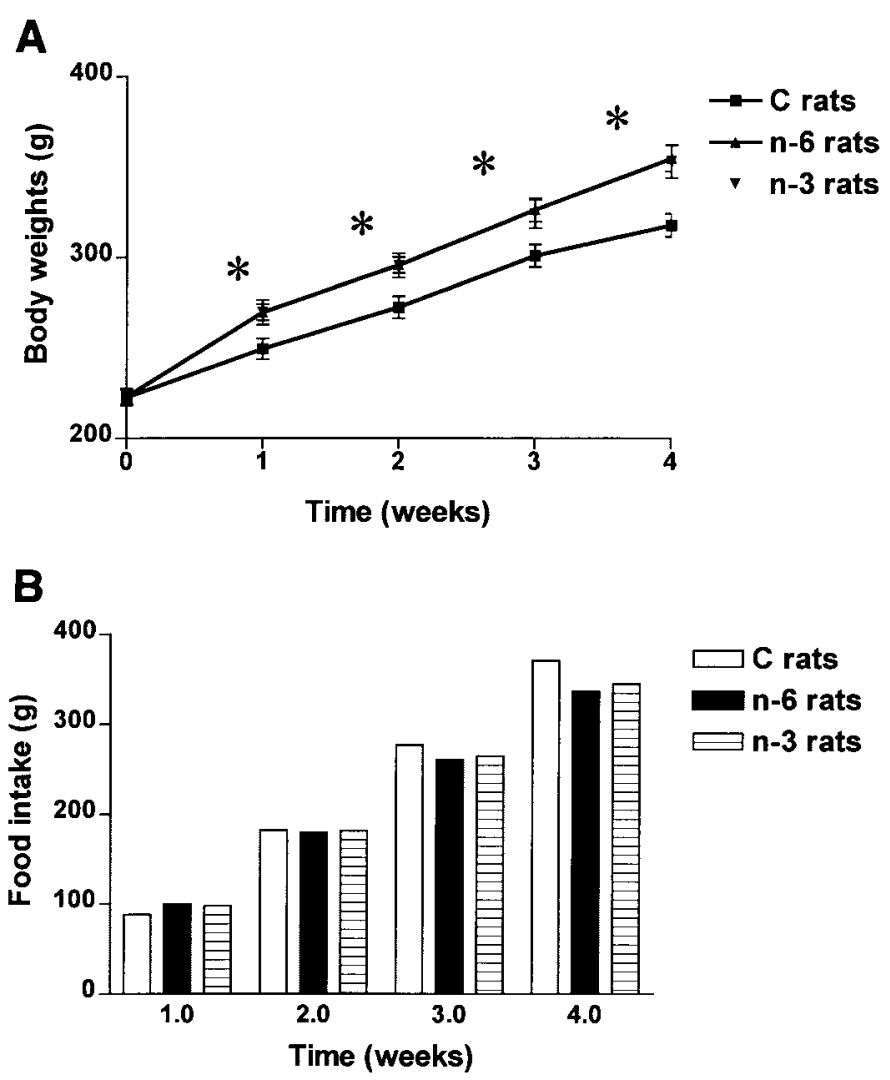

Fig. 1. Determination of body weights and food intake. Male Wistar rats (30 wk old) were divided into 3 groups of 10 and fed with a control diet, a high-fat diet rich in $n-6$ polyunsaturated fatty acid (PUFA), and a high-fat diet rich in n-3 PUFA. Body weight $(A)$ and food intake $(B)$ were measured every week for $4 \mathrm{wk}$. Results are expressed as means $\pm \mathrm{SE}$. $* P<0.05$.

$\mathrm{n}-3$ rats consumed 125.8 and $128.5 \mathrm{kcal} / \mathrm{day}$, respectively, whereas control rats consumed $118.7 \mathrm{kcal} / \mathrm{day}$.

Glucose and insulin plasma levels. Significantly higher glycemia and insulinemia were observed in n-6 and $n-3$ rats compared with control rats (Table 2 ). In n-6 and n-3 rats, insulin plasma levels were increased by $190 \%(P<0.05)$ and glucose plasma levels by $124 \%$ $(P<0.05)$ compared with the control group (100\%).

Impact of a hyperlipidic diet ( $n-6$ and $n-3)$ on the composition of muscle, liver, and adipose tissue lipids. The fatty acid content in membrane phospholipids of muscle, liver, and adipose tissue is shown in Fig. 2. As expected, the total amount of lipids in muscle, liver, and adipose tissue is significantly higher in n-3 and n-6 rats compared with control rats. However, the degree of enrichment is dependent on tissues. The positive impact of $n-3$ PUFA is mostly dependent on the ratio n-3 to n-6 or n-3 to total fatty acids. For this, we have also expressed the results as a ratio of PUFA (n-3) to total saturated fatty acid (Fig. 2A), PUFA (n-3) to PUFA (n-6) (Fig. 2B), and 20:5 (n-3) to 20:4 (n-6) (Fig. $2 C)$ in all studies. Figure 2 shows that the most affected or enriched tissue in n-3 PUFA was muscle compared with liver and adipose tissue. In addition, the ratio of PUFA (n-3) to PUFA (n-6), PUFA (n-3) to 
Table 2. Animal characteristics

\begin{tabular}{lcccc}
\hline \hline Diet & Body Wt, $\mathrm{g}$ & Wt Gain, $\mathrm{g}$ & Food Intake, g/day & Glucose, mmol/l \\
\hline Control & $317.7 \pm 6.3$ & $97.1 \pm 4.4$ & 23.2 & $8.2 \pm 0.0005$ \\
n-6 & $354.5 \pm 7.2^{*}$ & $131.5 \pm 7.1^{*}$ & 16.6 & $10.4 \pm 0.001^{*}$ \\
n-3 & $352.9 \pm 9.1^{*}$ & $129.8 \pm 6.6^{*}$ & 16.9 & $10.1 \pm 0.001^{*}$ \\
\hline
\end{tabular}

Data are means $\pm \mathrm{SE} ; n=10$ rats. $* P<0.05$.

total saturated fatty acid, or 20:5 (n-3) to 20:4 (n-6) was similar in adipose tissue of control and n-6 rats.

Effect of hyperlipidic ( $n-6$ and n-3) diets on liver and muscle insulin receptor density. In liver, hyperlipidic n-6 and n-3 diets significantly $(P<0.05)$ reduced IR number by 28.6 and $46.4 \%$, respectively, compared with rats fed a standard diet (Fig. 3A). IR affinity toward the hormone was not affected with an $\mathrm{EC}_{50}$ (concentration of cold insulin that inhibits $50 \%$ of ${ }^{125}$ I-insulin binding) of $27.8 \pm 3.4,29.6 \pm 6.4$, and
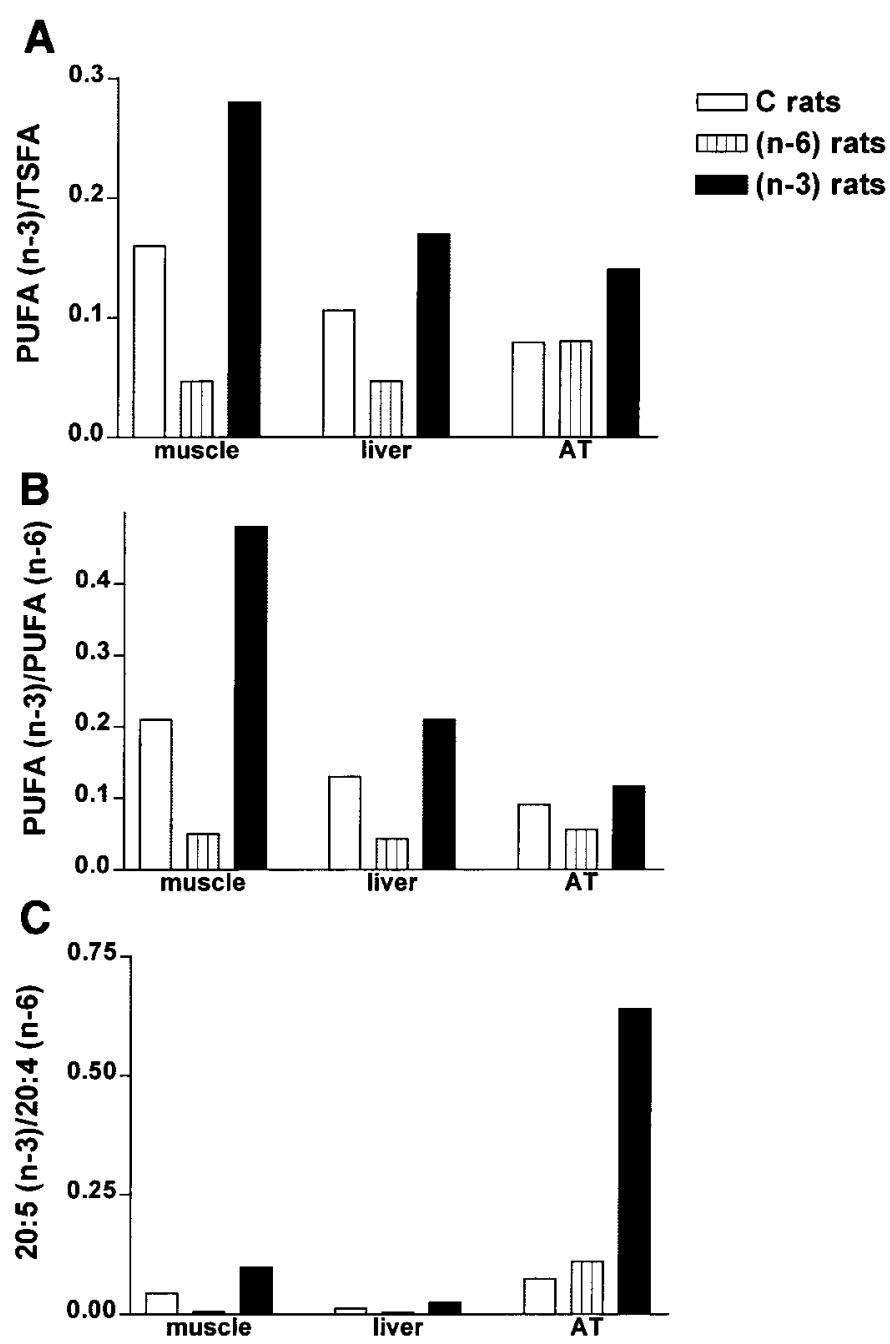

Fig. 2. Fatty acid composition of muscle, liver, and adipose tissue membrane phospholipids. Wistar rats (30 wk old) were divided into 3 groups and fed with the control (C rats), n- 6 PUFA (n-6 rats), or n-3 PUFA (n-3 rats) diet. After 4 wh of diet, phospholipid fatty acid composition was measured in liver, muscle, and adipose tissue. Results were expressed as PUFA (n-3)-total saturated fatty acid (TSFA) (A), PUFA (n-3)-PUFA (n-6) (B), and 20:5 (n-3)-20:4 (n-6) $(C)$.

$27.5 \pm 4 \mathrm{ng} / \mathrm{ml}$ in control, $\mathrm{n}-6$, and $\mathrm{n}-3$ rats, respectively (Fig. $3 A$, inset). In muscle, because of the high nonspecific binding of iodinated insulin to muscle crude membranes, IR content was estimated by Western blotting using specific anti-IR antibodies, as described in MATERIALS AND METHODS. Figure $3 B$ shows that muscle IR content was not significantly affected by the hyperlipidic diets, as estimated by the Western blot technique.

Impact of hyperlipidic diet (n-6 and n-3) on IR and IRS-1 tyrosine phosphorylation and PI 3'-kinase activity in liver. Intraperitoneal insulin injection increased liver IR tyrosine phosphorylation in control rats (-insulin $=58 ;+$ insulin $=87$, as arbitrary units measured using NIH Image Software), whereas in n-6 (-insulin $=82 ;$ +insulin $=66$ arbitrary units) and n-3 (-insulin $=62 ;$ +insulin $=64$ arbitrary units) rats, the insulin effect was completely abolished (Fig. 4A).

Insulin stimulated IRS-1 tyrosine phosphorylation in control rats ( - insulin $=100 ;$ +insulin $=138$ ) but not in $\mathrm{n}-6(-$ insulin $=123 ;+$ insulin $=107$ arbitrary

A

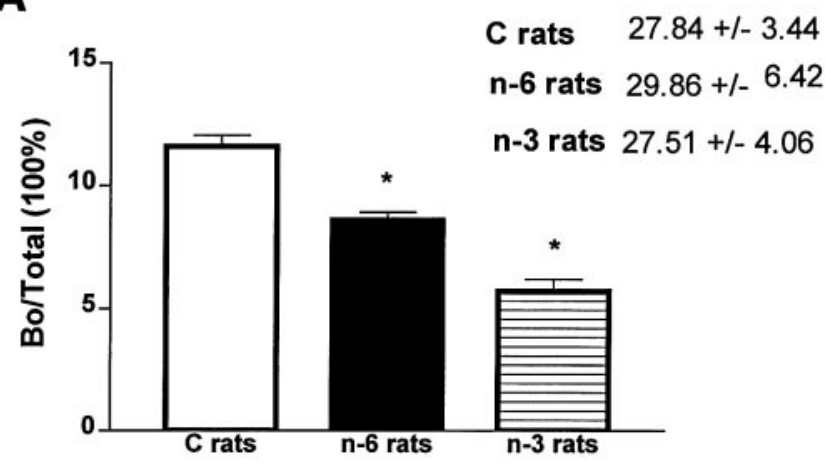

B

Blot : $\alpha$ IR

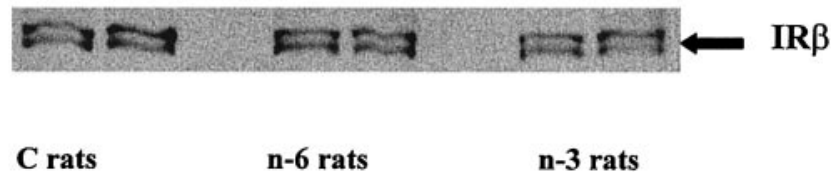

Fig. 3. Insulin receptor (IR) density in liver $(A)$ and muscle $(B)$ of $\mathrm{C}$, $\mathrm{n}-6$, and $\mathrm{n}-3$ rats. Wistar rats (5 wk old) were subjected to the control, n-6 PUFA, or n-3 PUFA diet for $4 \mathrm{wk}$, and then liver and muscles were removed. A: crude liver membranes were used to perform insulin-binding studies to measure insulin receptor density and insulin receptor affinity $\left(\mathrm{EC}_{50}\right)$. Results are expressed as means \pm SE. $* P<0.05$. 
A

IP : $\alpha$ PY20

Blot : $\alpha$ PY20

B

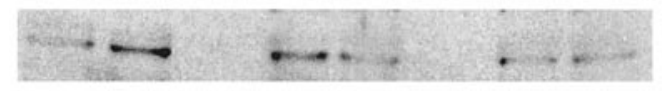

IR $\beta$

IP : $\alpha$ PY20

Blot : $\alpha$ IRS-1

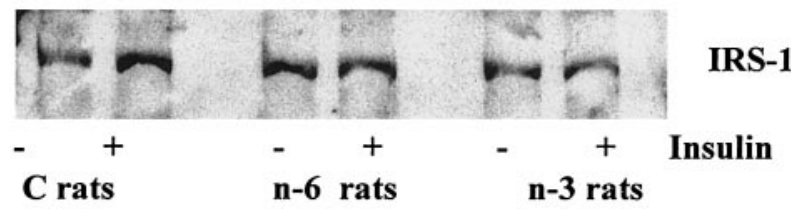

C

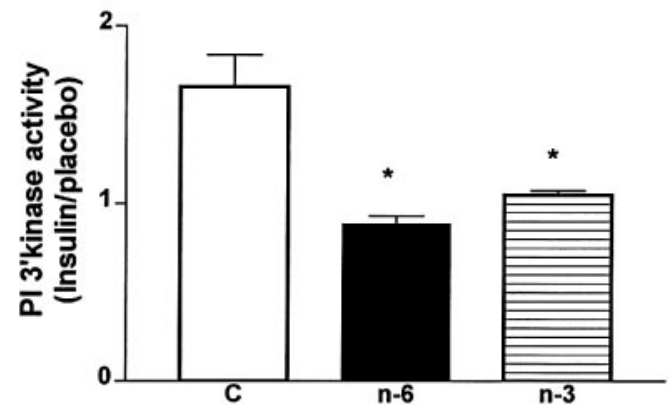

Fig. 4. Insulin receptor and insulin receptor substrate (IRS)-1 tyrosine phosphorylation and phosphatidylinositol (PI) 3'-kinase activity in liver. Male Wistar rats subjected to the control, n-6 PUFA, or n-3 PUFA diet for 4 wk received an ip dose of placebo (saline, -) or $100 \mathrm{mU}$ insulin/kg (+) and were killed after $7 \mathrm{~min}$ in the fed state. A: liver lysates were immunoprecipitated with $\alpha$-PY20 and blotted with $\alpha$-PY20 to identify the $\beta$-subunit of insulin receptor. $B$ : liver lysates were immunoprecipitated with $\alpha$-PY20 and blotted with $\alpha$-IRS- 1 to identify IRS-1. $C$ : liver lysates were immunoprecipitated with $\alpha$-PY20, and PI 3 '-kinase activity was measured in the immunoprecipitate. Results are expressed as ratio of insulin stimulated over placebo treatment and as means \pm SE. $* P<0.05 ; n=5$ rats.

units $)$ or $\mathrm{n}-3(-$ insulin $=101 ;+$ insulin $=83$ arbitrary units) rats (Fig. $4 B$ ).

Insulin stimulated PI 3 -kinase activity in control rats, whereas in both $\mathrm{n}-6(P<0.05)$ and $\mathrm{n}-3(P<$ $0.05)$ rats the insulin effect was completely abolished (Fig. $4 C$ ).

Impact of hyperlipidic diet (n-6 and n-3) on IR, IRS-1, and PI 3'-kinase activity in muscle. Insulin induced the tyrosine phosphorylation of IR in control rats $(-$ insulin $=120 ;+$ insulin $=140$ arbitrary units $)$ and $\mathrm{n}-3$ rats $(-$ insulin $=58 ;+$ insulin $=108$ arbitrary units) but not in $n-6$ rats $(-$ insulin $=125$; + insulin $=$ 124 arbitrary units). In addition, the basal tyrosine phosphorylation of the IR $\beta$-subunit was higher in $n-6$ rats than in control and n-3 rats (Fig. 5A).

In control rats, insulin induced the phosphorylation of IRS-1 $(-$ insulin $=140 ;$ +insulin $=217$ arbitrary units). In n-3 rats, insulin slightly induced the phosphorylation of IRS-1 $(-$ insulin $=105 ;+$ insulin $=120$ arbitrary units), whereas, in n-6 rats, the insulin effect was not observed and IRS-1 phopshorylation was even reduced $(-$ insulin $=194 ;+$ insulin $=129$ arbitrary units; Fig. 5B).

Insulin clearly stimulated PI 3 '-kinase activity in control and n-3 rats but not in n- 6 rats (Fig. $5 C$ ).

In addition, GLUT-4 protein content was reduced in $n-6$ rat muscles (191 arbitrary units) relative to control rats (214 arbitrary units), as band densities were quantified using NIH Image software. In n-3 rats, the muscle GLUT-4 content was similar to the level of control rats (207 arbitrary units; Fig. 5D).

A

IP : $\alpha$ PY20

Blot : $\alpha$ PY20

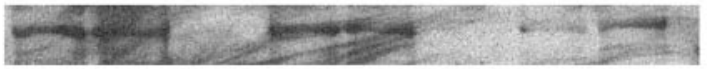

IR $\beta$

B IP : $\alpha$ PY20

Blot : $\alpha$ IRS-1

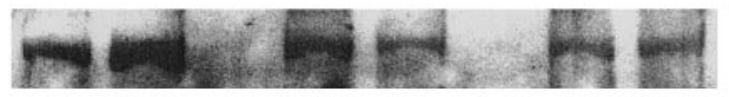

IRS-1

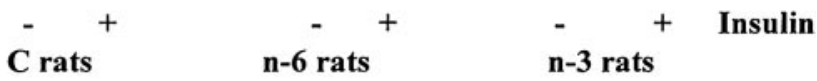

C

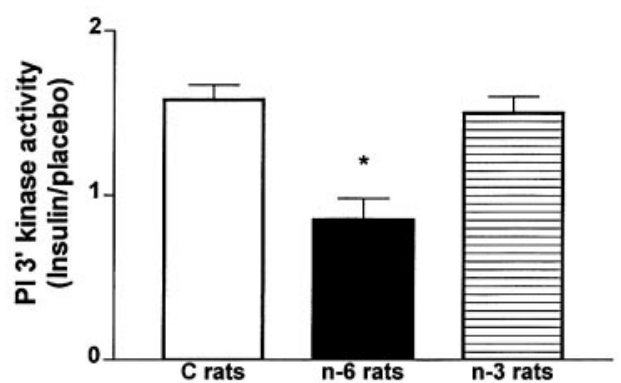

Blot : $\alpha$ Glut 4

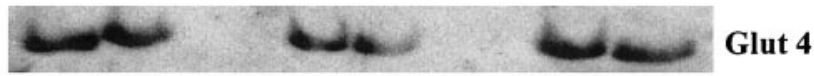

C

n-6 rats

n-3 rats

Fig. 5. Insulin receptor and IRS-1 tyrosine phosphorylation, GLUT-4 content, and PI 3'-kinase activity in muscle. Male Wistar rats (5 wk old) subjected to the control, n-6 PUFA, or n-3 PUFA diet for $4 \mathrm{wk}$ received an ip dose of placebo (saline, -) or $100 \mathrm{mU}$ insulin/kg (+) and were killed after $7 \mathrm{~min}$ in the fed state. $A$ : muscle lysates were immunoprecipitated with $\alpha$-PY20 and blotted with $\alpha$-PY20 to identify the $\beta$-subunit of insulin receptor. $B$ : muscle lysates were immunoprecipitated with $\alpha$-PY20 and blotted with $\alpha$-IRS-1 to identify IRS-1. $C$ : muscle lysates were immunoprecipitated with $\alpha$-PY20, and PI 3'-kinase activity was measured in the immunoprecipitate. Results are expressed as a ratio of insulin stimulated over placebo treatment and as means $\pm \mathrm{SE}$. $* P<0.05 ; n=5$ rats. $D$ : muscle lysates from placebo-treated animals were subjected to Western blot and revealed with $\alpha$-GLUT-4. Data are representative of two different animals from each treatment. 
Adipose tissue IR, IRS-1, PI 3'-kinase regulatory subunit (p85), GLUT-4, and leptin mRNA expressions. To study the impact of the high-fat diets (n-6 or n- 6 and $\mathrm{n}-3$ ) on insulin receptor signaling components (IR, IRS-1, p85, and GLUT-4) and on leptin, the corresponding mRNAs were quantified using RT-PCR and were expressed as the ratio over the expression of $18 \mathrm{~S}$ RNA, as described in MATERIALS AND METHODS. Figure 6 shows that IR and IRS-1 mRNA expression was not altered by the high-fat diets. The expression of the regulatory subunit of PI 3 '-kinase (p85) was significantly $(P<0.05)$ reduced in $n-6$ and $n-3$ rats compared with control rats. GLUT-4 and leptin expressions were significantly diminished in n- 6 rats, whereas their expression was similar in $\mathrm{n}-3$ rats compared with control rats (Fig. 6).

\section{DISCUSSION}

The present study shows that a high-PUFA diet (n-6 or $\mathrm{n}-3$ ) increases body weight and energy consumption and is associated with elevated glycemia and insulinemia. Furthermore, an n- 6 or n- 6 and n-3 high-PUFA diet also affects target tissue lipid composition (liver, muscle, and adipose tissue), and muscle appears to be most enriched in the n-3 PUFA diet. This indicates that muscle, liver, and adipose tissue were differently affected by the fatty acid composition of a diet. The results from this study also demonstrate that a highPUFA diet in rats affects the early steps of insulin signaling, depending on both the fatty acid composition of the diet and the tissue in which insulin exerts its effects. We clearly showed that both $n-6$ and $n-6$ and $\mathrm{n}-3$ high-fat diets induced a striking reduction in insulin receptor density in liver and a blunting of the effect of insulin on IR and IRS-1 tyrosine phosphorylation and PI 3'-kinase activity. This indicates a profound alteration of the early steps of insulin receptor signaling in liver. To our knowledge, this is the first study reporting such impact of an n-6 or n-6 and n-3 highPUFA diet on liver. Our results contrast with those

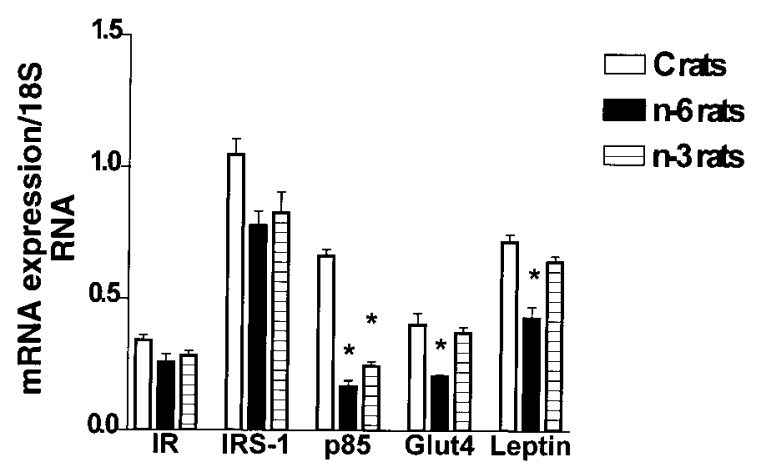

Fig. 6. Insulin receptor, IRS-1, PI 3'-kinase regulatory (p85) subunit, GLUT-4, and leptin mRNA expression in adipose tissue. Total RNA was prepared from adipose tissue of 5 -wk-old male Wistar rats subjected to the control, n-6 PUFA, or n-3 PUFA diet for 4 wk. Total RNA was used to perform RT-PCR, which was primed with specific primers for IR, IRS-1, p85, GLUT-4, or leptin. The intensity of mRNA expression was measured using NIH Image software, and results are expressed as means $\pm \mathrm{SE} .{ }^{*} P<0.05 ; n=5$. reported in the liver of rats fed a high-saturated-fat diet (1), where IRS-1 tyrosine phosphorylation was maintained and PI 3'-kinase activity was increased. Taken together, our results and those from Anai et al. (1) indicate that the type of fatty acids (saturated vs. PUFA) in a high-fat diet has a major specific impact on insulin signaling in liver. They also suggest that the impact of dietary fatty acid on hepatic glucose production may involve PI 3'-kinase activity and that the liver insulin resistance induced by a high-fat diet in rats is prevented when fatty acids (saturated, monounsaturated, or n-6 PUFA) are partially substituted with n-3 PUFA (27). We can speculate that glucose-6-phosphatase and/or glucokinase activities could be the target of n-3 PUFA inasmuch as an increase in glucose cycle activity was observed in liver of rats with liver insulin resistance induced by a high-fat diet (21).

In muscle, converse to what was observed in the liver, the n-6 diet had different effects from those of a mixed n-6 and n-3 diet, and this may corroborate the fact that muscle and liver are differently affected by the fatty acid composition of diets. The n- 6 PUFA led to the blunting of IR and IRS-1 tyrosine phosphorylation in response to insulin injection despite a mild change in IR density. In addition, the stimulating effect of insulin on PI 3'-kinase activity was also blunted, and GLUT-4 protein was depressed. In rats fed the $n-6$ and n-3 diet, insulin signaling was not altered despite the partial reduction in IRS-1 phosphorylation. Thus, in contrast to liver, the partial substitution of $n-3$ PUFA for n-6 PUFA almost completely maintains the insulin sensitivity of the IR signaling cascade compared with control rats. Importantly, the total amount of GLUT-4 was also maintained at the level of control rats. These results may at least partially explain the recovery of glucose uptake after substitution of n-6 PUFA with n-3 PUFA in a high-fat diet (28). Indeed, the rate of glucose uptake depends on the amount of GLUT-4 in membrane cells in response to insulin. Because GLUT-4 translocation (not determined in our study) is related to PI 3'-kinase activity (5), it is likely that muscle glucose uptake by n-3 PUFA rats was related to the normal insulin signaling cascade activation. Despite normal sensitivity of insulin signaling in muscle, $n-3$ rats display subnormal glycemia and insulinemia like $\mathrm{n}-6$ rats, which strongly suggests an insulin resistance. This is most likely attributed to the similar degree of obesity associated with insulin resistance and/or the preexistence of a liver insulin resistance limiting the beneficial effect of n-3 PUFA. However, such explanations remain hypothetical, since our study did not aim to determine hepatic glucose production and tissue glucose utilization.

In n-3 and n-6 rats, the adiposity was higher compared with control rats, which reduced protein extraction yield in the adipose tissue. Therefore, we have investigated the expression of insulin signaling components at the level of RNA messengers. We show that $n-6$ and $n-6$ and n-3 diets did not alter IR and IRS-1 expressions, but both diets reduced the expression of the regulatory subunit (p85) of PI 3'-kinase. This dif- 
fers from what has been reported during a high saturated fat diet where both IRS-1 and p85 expressions were reduced (1). Interestingly, GLUT-4 and leptin expressions were reduced after the n- 6 diet and not after the n-6 and n-3 diet compared with control rats. These observations demonstrate that, in adipose tissue, the effect of n-3 PUFA on p85 expression dissociated from their effect on GLUT-4. Because the increased adiposity associated with insulin resistance may affect leptin expression, we have also studied the impact of an n-3 diet compared with an n-6 diet, and we showed that the expression of leptin was altered in n-6 rats but not in $\mathrm{n}-3$ rats. The alteration of leptin expression in $\mathrm{n}-6$ rats was not related to energy balance, weight gain, or energy intake because these parameters are similar to those of n-3 rats. Therefore, the effect of a high-fat diet on leptin expression in adipose tissue is primarily determined by the type of fatty acids ingested and not by weight gain. It is important to note that the difference in leptin expression did not affect energy intake during the three experimental diets. Whether the parallel effect of n-3 PUFA on leptin and GLUT-4 expression results from a common mechanism was not assessed in our study.

The basic mechanisms sustaining the tissue specificity of the effect of an n-6 and n-6 and n-3 diet remain unclear. During the n-6 and n-3 diet, n-3 PUFA incorporated in membrane phospholipids of liver, muscle, and adipose tissue. The incorporation of n-3 fatty acids in phospholipids relative to the control diet was not strikingly different between tissues during the $n-6$ and $\mathrm{n}-3$ diet. However, the incorporation of $n-3$ PUFA in triglycerides was quite higher in liver than in muscle or adipose tissue. Whether the incorporation of $n-3$ PUFA in membrane phospholipids or in triglycerides is a prerequisite for their effect on insulin signaling remains to be determined. Data in rats and humans showing a relationship between glucose uptake in muscle and unsaturation of membranes phospholipids (25, 29) suggest that, whatever the basic mechanism, alteration of the fatty acid content of membranes could play a role.

The antagonist effect of n-3 PUFA against the alteration of the early steps of insulin signaling and as the expression of the regulatory subunit of PI 3'-kinase (p85) in adipose tissue is of special interest, especially regarding potential implications for patients with type 2 diabetes. In such patients, a defect in the PI 3 '-kinase pathway in muscle (2) and a defect in the expession of p85 in muscle and adipose tissue in response to insulin have been demonstrated (33). Whether n-3 PUFA could restore the insulin sensitivity of PI 3'-kinase activity and expression in diabetic subjects merits further investigation. The antagonizing effect of $n-3$ PUFA against the reduction of leptin expression in adipose tissue could also have major implications for insulin resistance in humans. Unger et al. (33) recently proposed that one of the roles of leptin was to confine triglyceride storage in adipocytes, preventing excessive depots in other tissues. An excess storage of triglycerides in muscle and in $\beta$-cells participates in insulin resistance (29), defective insulin secretion via the Randle cycle, and lipotoxicity (34), which reinforces the two main alterations responsible for type 2 diabetes. The restoration of leptin expression could also be important in restoring muscle glucose utilization inasmuch as leptin administration in rats stimulates glucose uptake in muscle independent of any alteration of GLUT-4 expression or protein abundance (34).

In summary, this is to our knowledge the first study to establish a clear effect of a high-fat diet enriched in n-3 fatty acids on insulin signaling. A high-fat diet enriched in n-3 fatty acids maintained IR, IRS-1 tyrosine phosphorylation, PI 3'-kinase activity, and total GLUT-4 content in muscle but not in liver. At the level of gene expression, a high-fat diet enriched in n-3 fatty acids partially maintained the expression of $\mathrm{p} 85$ and totally that of GLUT-4 and leptin mRNA in adipose tissue. Despite these positive effects, rats fed with n-3 PUFA still showed hyperglycemia and hyperinsulinemia, indicating that liver insulin sensitivity impairment strongly contributes to insulin resistance.

We are grateful to Dr. J. Simon for helpful discussions concerning the experimental design of the experiment and to Michel Derouet for technical support.

\section{REFERENCES}

1. Anai M, Funaki M, Ogihara T, Kanda A, Onisi Y, Sakoda Inukai K, Nawano M, Fukusima Y, Yazaki Y, Kikuci M, Oka Y, and Asano T. Enhanced insulin-stimulated activation of phosphatidylinositol 3-kinase in the liver of high-fat-fed rats. Diabetes 48: 158-169, 1999.

2. Andreelli F, Lavile M, Ducluzeau PH, Vega N, Vallier P, Khalfallah Y, Riou JP, and Vidal $\mathbf{H}$. Defective regulation of phosphatidylinositol-3-kinase gene expression in skeletal muscle and adipose tissue of non insulin dependent diabetes mellitus patients. Diabetologia 42: 358-364, 1999.

3. Cline GW, Petersen KF, Krssak M, Shen J, Hundal RS, Trajanoski Z, Inzucchi S, Dresner A, Rothman DL, and Shulman GI. Impaired glucose transport as a cause of decreased insulin-stimulated muscle glycogen synthesis in type 2 diabetes. N Engl J Med 341: 240-246, 1999.

4. Clore JN, Stillman J, and Sugerman H. Glucose-6-phosphatase flux in vitro is increased in type 2 diabetes. Diabetes 49: 969-974, 2000.

5. Cusi K, Maezono K, Osman A, Pendergrass M, Patty ME, Pratipanawatr T, DeFronzo RA, Kahn CR, and Mandarino LJ. Insulin resistance differentially affects the PI 3-kinase- and MAP kinase-mediated signaling in human muscle. J Clin Invest 105: 311-320, 2000.

6. Dupont J, Derouet M, Simon J, and Taouis M. Effect of nutritional state on the formation of a complex involving insulin receptor, I.R.S-1, the $52 \mathrm{kDa}$ Src homology/collagen protein (Shc) isoform, and phosphatidyl inositol 3 ' kinase activity. Biochem $J$ 335: 293-300, 1998.

7. Ezaki O, Tsuji E, Momomura K, Kasuga M, and Itakura $H$. Effects of fish and safflower oil feeding on subcellular glucose transporter distributions in rats adipocytes. Am J Physiol Endocrinol Metab 263: E94-E101, 1992.

8. Fickova M, Hubert P, Cremel G, and Leray C. Dietary (n-3), and (n-6) poly-unsaturated fatty acids rapidly modify acid composition and insulin effects in rat adipocytes. J Nutr 128: 512$519,1998$.

9. Folch J, Lees M, and Sloane-Stanley GH. A simple method for the isolation and purification of total lipids from animal tissues. J Biol Chem 226: 497-509, 1957.

10. Gasperikova D, Sebokova E, and Klimes I. Intracellular insulin signalling, glucose transport, and in vivo insulin action 
in selected rat models of insulin resistance. Endocr Regul 30: 207-228, 1996.

11. Grunleger SW and Thenen ML. Decreased insulin binding, glucose transport, and glucose metabolism in soleus muscle of rats fed a high fat diet. Diabetes 31: 232-237, 1982.

12. Jucker BM, Cline GW, Barucci N, and Shulman GI. Differential effects of safflower oil versus fish oil feeding on insulinstimulated glycogen synthesis, glycolysis, and pyruvate dehydrogenase flux in skeletal muscle. Diabetes 48: 134-140, 1999.

13. Kahn BB. Dietary regulation of glucose transporter gene expression: tissue specific effects in adipose cells and muscle. $J$ Nutr 124: 1289S-1295S, 1994.

14. Kahn BB and Pedersen O. Suppression of GLUT4 expression in skeletal muscle of rats that are obese from high fat feeding but not from high carbohydrate feeding or genetic obesity. Endocrinology 132: 13-22, 1993.

15. Kim YB, Nakajima R, Matsuo $T$, Inoue $T$, Sekine $T$, Komuro M, Tamura K, Tokuyama K, and Suzuki M. Gene expression of insulin signal-transduction pathway intermediates is lower in rats fed a beef tallow diet than in rats fed a safflower oil diet. Metabolism 45: 1080-1088, 1996.

16. Kraegen EW, Clark PW, Jenkins AB, Daley EA, Chisholm DJ, and Storlien LH. In vivo insulin resistance in individual peripheral tissues of the high fat fed rat: assessment by euglycemic clamp plus deoxyglucose administration. Diabetologia 29: $192-198,1986$.

17. Kraegen EW, Clark PW, Jenkins AB, Daley EA, Chisholm DJ, and Storlien LH. Development of muscle insulin resistance after liver insulin resistance in high fat fed rats. Diabetes 40:1397-1403, 1991.

18. Levy-Toledano R, Taouis M, Baettler DH, Gorden P, and Taylor P. Insulin induced activation of P.I $3^{\prime}$ kinase Demonstration that the p85 subunit binds directly to the $\mathrm{COOH}$ terminus of the insulin receptor in intact cells. $J$ Biol Chem 269: 31178-31182, 1994.

19. Liu S, Baracos VE, Quinney HA, and Clandinin MT. Dietary omega-3 and polyunsaturated fatty acids modify fatty acyl composition and insulin binding in skeletal-muscle sarcolemma. Biochem J 299: 831-837, 1994.

20. McGarry JD and Dobbins RL. Fatty acids, lipotoxicity and insulin secretion. Diabetologia 42: 128-138, 1999.

21. Oakes ND, Cooney GJ, Camilleri S, Chisholm DJ, and Kraegen EW. Mechanisms of liver and muscle insulin resistance induced by chronic high-fat feeding. Diabetes 46: 17681774, 1997.

22. Roden M, Price TB, Perseghin G, Petersen KF, Rothman DL, Cline GW, and Shulman GI. Mechanism of free acidinduced insulin resistance in humans. J Clin Invest 97 : 2859$2865,1996$.
23. Rosholt MN, King PA, and Horton ES. High-fat diet reduces glucose transporter responses to both insulin and exercise. Am $J$ Physiol Regulatory Integrative Comp Physiol 266: R95-R101, 1994.

24. Sebokova I and Klimes E. Dietary regulation of glucose transport in animal models of insulin resistance. Nutrition 13: 152153, 1997.

25. Storlien LH, Baur LA, Kriketos AD, Pan DA, Cooney GJ, Jenkins AB, Calvert GD, and Campbell LV. Dietary fats and insulin action. Diabetologia 39: 621-631, 1996.

26. Storlien LH, James DE, Burleigh KM, Chislholm DJ, and Kraegen EW. Fat feeding causes widespread in vivo insulin resistance, decreased energy expenditure, and obesity in the rat. Am J Physiol Endocrinol Metab 251: E576-E583, 1986.

27. Storlien LH, Jenkins AB, Chisholm DJ, Pascoe WS, Khouri S, and Kraegen EW. Influence of dietary fat composition on development of insulin resistance in rats. Diabetes 40: 280-289, 1991.

28. Storlien LH, Kraegen EW, Chisholm DJ, Ford GL, Bruce DG, and Pascoe WS. Fish oil prevents insulin resistance induced by high fat feeding in rats. Science 237: 885-888, 1987.

29. Storlien LH, Kriketos D, Jenkins AB, Baur LA, Pan DA, Tapsell LC, and Calvert GD. Does dietary fat influence insulin action. Ann NY Acad Sci 827: 287-301, 1997.

30. Taouis M, Derouet M, Caffin JP, Chavanieu A, and Simon J. Insulin receptor, and insulin sensitivity in a chicken hepatoma cell line. Mol Cell Endocrinol 96: 113-123, 1993.

31. Taouis M, Levy-Toledano R, Taylor SI, and Gorden P. Rescue, and activation of a binding-deficient insulin receptor. Evidence for intramolecular transphosphorylation. J Biol Chem 269: 14912-14918, 1994.

32. Taouis M, Levy-Toledano R, Taylor SI, and Gorden P. Structural basis by which a recessive mutation in the $\alpha$ subunit of the insulin receptor affects insulin binding. J Biol Chem 269: 27762-27766, 1994.

33. Unger RH, Zhou YT, and Lorci L. Regulation of fatty acid homeostasis in cells: novel role of leptin. Proc Natl Acad Sci USA 96: 2327-2332, 1999.

34. Wang JL, Chinookoswong N, Scully S, Qi M, and Shi ZQ. Differential effects of leptin in regulation of tissue glucose utilization in vivo. Endocrinology 140: 2117-2124, 1999.

35. Wilkes JJ, Bonen A, and Bell RC. A modified high-fat diet induces insulin resistance in rat skeletal muscle but not adipocytes. Am J Physiol Endocrinol Metab 275: E679-E686, 1998.

36. Zierath JR, Houseknecht KL, Gnudi L, and Kahn BB. High fat feeding impairs insulin-stimulated GLUT4 recruitment via an early insulin-signaling defect. Diabetes 46: 215-223, 1997. 